\title{
Cultivation and characterization of pterygium as an ex vivo study model for disease and therapy
}

\author{
Natasha Josifovska ${ }^{a}$, Dóra Júlia Szabóa ${ }^{a}$, Richárd Nagymihály ${ }^{a}$, Zoltán Veréb ${ }^{\mathrm{a}}$, Andrea Facskóa \\ Ketil Eriksen ${ }^{\mathrm{b}}$, Morten C. Moe ${ }^{\mathrm{b}}$, Goran Petrovski ${ }^{\mathrm{a}, \mathrm{b}, *}$ \\ a Stem Cells and Eye Research Laboratory, Department of Ophthalmology, Faculty of Medicine, University of Szeged, Koranyi Fasor 10-11, 6720 Szeged, Hungary \\ b Center for Eye Research, Department of Ophthalmology, Oslo University Hospital and University of Oslo, Kirkeveien 166, N-0407 Oslo, Norway
}

\section{A R T I C L E I N F O}

\section{Keywords:}

Pterygium

Long-term cultures

Tissue engineering

Mitomycin C

IL-6

IL-8

\begin{abstract}
A B S T R A C T
Purpose: Development of ex vivo model to study pathogenesis, inflammation and treatment modalities for pterygium.

Methods: Pterygium obtained from surgery was cultivated (3 months). Gravitational attachment method using viscoelastic facilitated adherence of graft and outgrowing cells. Medium contained serum as the only growth supplement with no use of scaffolds. Surface profiling of the multi-layered cells for hematopoietic- and mesenchymal stem cell markers was performed. Examination of cells by immunohistochemistry using pluripotency, oxidative stress, stemness, migration and proliferation, epithelial and secretory markers was performed. The effect of anti-proliferative agent Mitomycin C upon secretion of pro-inflammatory cytokines IL-6 and IL-8 was assessed.

Results: Cells showed high expression of migration- (CXCR4), secretory- (MUC1, MUC4) and oxidative damage(8-OHdG) markers, and low expression of hypoxia- (HIF-1 $\alpha$ ) and proliferation- (Ki-67) markers. Moderate and low expression of the pluripotency markers (Vimentin and $\Delta \mathrm{Np} 63$ ) was present, respectively, while the putative markers of stemness (Sox2, Oct4, ABCG-2) and epithelial cell markers- (CK19, CK8-18) were weak. The surface marker profile of the outgrowing cells revealed high expression of the hematopoietic marker CD47, mesenchymal markers CD90 and CD73, minor or less positivity for the hematopoietic marker CD34, mesenchymal marker CD105, progenitor marker CD117 and attachment protein markers while low levels of IL-6 and IL-8 secretion ex vivo, were inhibited upon Mitomycin C treatment.

Conclusion: Ex vivo tissue engineered pterygium consists of a mixture of cells of different lineage origin, suitable for use as a disease model for studying pathogenesis ex vivo, while opening possibilities for new treatment and prevention modalities.
\end{abstract}

\section{Introduction}

Pterygium is a common ocular surface disorder characterized by an active wing-shaped overgrowth of epithelial and fibrovascular tissue growing from the conjunctiva towards the limbus and onto the cornea, thus giving cosmetic alterations to the ocular surface and in advanced cases impairing vision [1-4]. It consists of a head which falls onto the anterior cornea, a neck which covers the superficial limbus, and a body which overlies the sclera. The first sign of pterygium is formation of a cap which appears as halo in front of the head and goes deep into the epithelium without respecting the limbal epithelium stem cell border [5]. It is not fully known whether the stem cell deficiency alone or other factors drive the centripetal migration of the pterygium cells onto the cornea, or how sclera support may play a role in the process.
The pathogenesis of pterygium remains uncertain, although it is thought to be mainly caused by ultraviolet (UV) radiation. A wide range of alternative pathogenic factors have been proposed, including viral infections, epigenetic aberrations, epithelial-mesenchymal transition, immunologic and anti-apoptotic mechanisms, angiogenic and lymphangiogenic stimulation, deregulation of extracellular matrix (ECM) modulators and growth factors, inflammation cascades, recruitment of bone-marrow-derived stem- and progenitor cells, and modifications in the cholesterol metabolism. Most of these factors are rather related to the development and maintenance of the disease than to its origin [6].

In the present study, cells were adherently cultivated and grown out of the pterygium using gravitational force from viscoelastic material for more than three months or until they formed multi-layered structures. Surface marker profiling using hematopoietic- and mesenchymal stem

\footnotetext{
* Corresponding author at: Department of Ophthalmology, University of Szeged, Korányi fasor 10-11, 6720, Szeged, Hungary.

E-mail address: petrovski.goran@med.u-szeged.hu (G. Petrovski).
} 


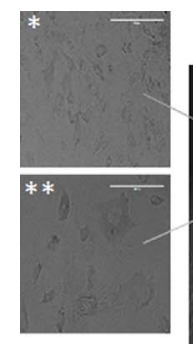

A
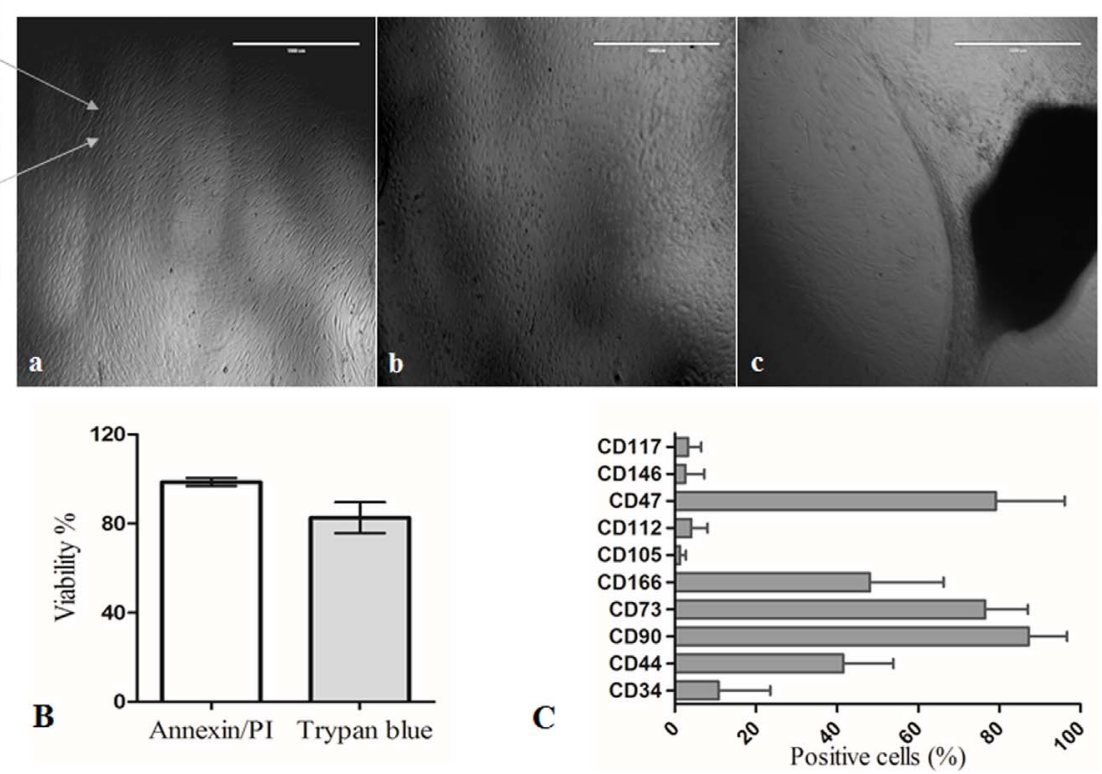

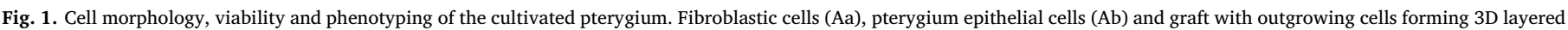

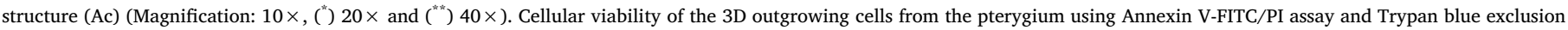
test (B). Cell surface markers phenotyping of the 3D outgrowing cells by FACS analysis; a plot of the percent positive cells versus different markers is shown as mean \pm SD (C).

\section{Table 1}

Immunophenotyping of the multi-layered outgrowing pterygium cells. Expression of different surface markers shown as percent (\%).

\begin{tabular}{lll}
\hline \multicolumn{2}{l}{ Multi-layered outgrowing pterygium cells } & \\
\hline HSC markers & CD34 & $10.8 \pm 12.7 \%$ \\
& CD47 & $79.1 \pm 17 \%$ \\
Progenitor marker & CD117/c-kit & $3.3 . \pm 3.2 \%$ \\
MSC markers & CD90 & $87.2 \pm 9.5 \%$ \\
& CD73 & $76.4 \pm 11 \%$ \\
ECM attachment proteins markers & CD105 & $1.3 \pm 1.4 \%$ \\
& CD146/MCAM & $2.6 \pm 4.7 \%$ \\
& CD166/ALCAM & $48.1 \pm 18.1 \%$ \\
& CD44/H-CAM & $41.5 \pm 12.3 \%$ \\
& CD112/Nectin-2 & $4.1 \pm 4 \%$ \\
\hline
\end{tabular}

cell (HSC and MSC) markers to determine the possible phenotype and origin of these cells was also used. Furthermore, full characterization of markers for pluripotency and stemness: Vimentin (Vim), tumour/ transformation-related protein 63 (p63/TP63), Sex Determining Region Y-related HMG-box (Sox2), Octamer-binding transcription factor 4 (Oct4), and ATP-binding cassette sub-family G member 2 (ABCG-2), oxidative stress: 8-hydroxy-2' - deoxyguanosine (8-OHdG) and hypoxia-inducible factor 1 alpha (HIF-1 $\alpha$ ), migration and proliferation:C-X-C chemokine receptor type 4 (CXCR4) and (Ki-67/ MKI67), epithelial: Cytokeratin (CK19 and 8-18) and secretory markers: Mucin (MUC1 and MUC4) was done.

Inflammatory processes in the pterygium can cause reactive wound formation, which may induce dysregulated and inappropriate tissue remodelling, fibrotic proliferation, enhanced vascularization and deposition of ECM, leading to formation of hypertrophic scarring and recurrence. Inflammation can induce the angiogenic pathways, which can result in neovascularization and contribute to further pterygium growth. Mitomycin C (MMC), an anti-mitotic agent often used in recurrent pterygium ablation surgery can induce apoptosis of keratocytes and myofibroblasts [6]. Herein, the effect MMC has upon the secretion of pro-inflammatory cytokines, interleukin 6 (IL-6) and IL-8 was checked after repeated pterygium graft cultivation, thus resembling closely its application in vivo for recurrent cases.

\section{Materials and methods}

\subsection{Pterygium harvesting and cultivation}

All tissue collection complied with the Guidelines of the Helsinki Declaration and was obtained from surgery following a patient signed consent. The tissue harvesting was approved by the Local Committee for Medical Research Ethics at University of Oslo. The removed graft was then cultivated in 24-well cell culture plates using Dulbeccomodified Eagle's medium (DMEM) with $4.5 \mathrm{~g}$ glucose/L supplemented, $10 \%$ fetal bovine serum (FBS) and $200 \mathrm{mM} / \mathrm{mL}$ L-glutamine (SigmaAldrich, Germany), as well as $1 \%$ antibiotic/antimycotic solution (PAA, Pasching, Austria). Before cultivation, viscoelastic (ProVisc, Alcon, Fort Worth, TX, USA) [7] was added on top of the explant to allow flattening and adherence of the tissue onto the surface of the well. Medium was changed every other day and the tissues were cultivated for more than three months or until they formed multi-layered cells which could be lifted easily from the cell culture plate by Colibri forceps before fixation and further analysis.

\subsection{Cell viability assay}

Cell viability was determined using Annexin V-Fluorescein isothiocyanate (FITC)/Propidium Iodide (PI) assay (MBL International, Woburn, MA, USA) and trypan blue exclusion test (Sigma Aldrich, MO, USA). For both assays, the cells were collected by trypsinization in culturing media, then centrifuged and resuspended in Binding Buffer for the Annexin V-FITC/PI assay. Furthermore, they were stained with Annexin V-FITC, PI, and Annexin V-FITC/PI and analysed by Flowing Software 2.5 (PerttuTerho, Turku Centre for Biotechnology, University of Turku, Finland). $50 \mu \mathrm{L}$ cell suspension was mixed with equal parts of trypan blue solution and cells were counted in a Hemocytometer (Burker chamber).

\subsection{Immunophenotyping of cells}

The immunophenotype of the long-term multi-layered cultures of pterygium containing outgrowing cells was determined by flow cytometry. FITC-, R-phycoerythrin (PE)- and allophycocyanin (APC)- con- 

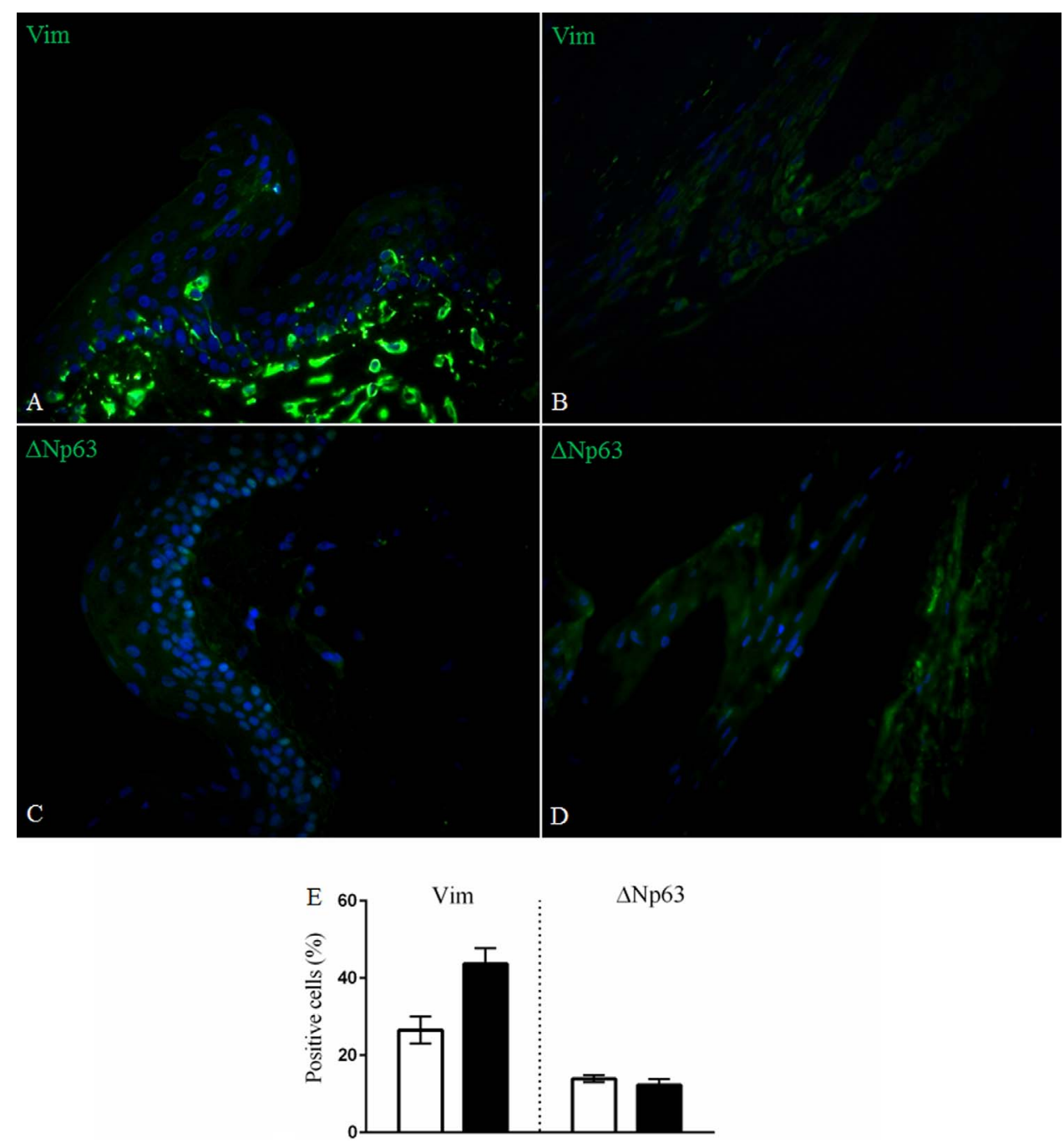

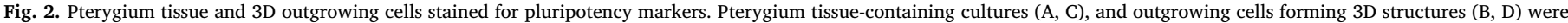

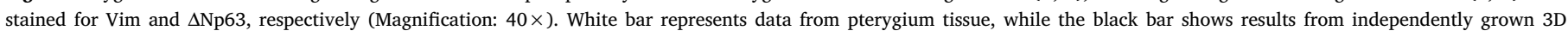
outgrowing cells. Data are expressed as mean \pm SD.

jugated antibodies were used to measure the expression of CD34, CD44, CD90/Thy-1, CD73, CD105 and CD166/ALCAM (all from Biolegend, San Diego, CA, USA); CD47, CD117/c-kit, CD146/MCAM, CD112 (all from R \& D Systems, Minneapolis, MN, USA) (for further details refer to S1Table). Samples were measured by FACS Calibur flow cytometer (BD Biosciences Immunocytometry Systems) and data were analysed by Flowing Software 2.5 (PerttuTerho, Turku Centre for Biotechnology, University of Turku, Finland).

\subsection{Immunofluorescent staining}

Pterygium obtained right after surgery and that cultivated as longterm multi-layered cultures were collected and fixed in $4 \%$ paraformaldehyde at room temperature, later dehydrated in ascending alcohol series and embedded in paraffin; 3-4 $\mu \mathrm{m}$ thick tissue sections were prepared using a rotary microtome, then mounted onto histological slides. After heat-induced antigen retrieval and blocking, immunofluorescent labelling was performed. The samples were characterized for markers of pluripotency and stemness (Vim, $\Delta$ Np63, Sox2, Oct4, ABCG2 ,), oxidative stress (8-OHdG, HIF-1 $\alpha$ ), migration and proliferation(CXCR4 and Ki-67), epithelial- (CK19 and 8-18) and secretory markers (MUC1 and MUC4) (S2 Table summarizes the primary antibodies and dilutions used for immunofluorescent staining). Nuclear staining was performed using 4', 6-diamidino-2-phenylindole (DAPI). Fluorescent images were taken by a ZEISS Axio Observer.Z1 (ZEISS, Oberkochen, Germany) microscope. The quantification of positive cells was carried out using standard ImageJ software by three independent individuals. The number of positive cells on the full field of view was taken into account with the help of nuclear (DAPI) staining. Multiple pictures were taken of each sample and the results averaged out as mean \pm standard deviation (SD).

\subsection{Secretion of inflammatory cytokines by ELISA}

High glucose-containing DMEM medium with 5\% FBS was applied to the multi-layered outgrowing cells and the supernatants were collected after $24 \mathrm{~h}$. In addition, treatment of the cells with $0.5 \mathrm{mg}$ / mL MMC (Kyowa, Takeda Belgium-Brussels) was applied for 5 min and exchanged by fresh medium for another $15 \mathrm{~min}$ prior to the supernatant collection, thus resembling the clinical use of MMC in surgery. Limbal epithelial stem cell (LESC) cultures cultivated in high glucose-containing medium with $10 \%$ FBS were also used as a control. The secreted cytokines, IL-6 and IL-8, were analysed by a commercial ELISA kit (R \& D, Germany) according to the manufacturer's protocol. Three independent experiments were performed on outgrowing cells from four different pterygium donors. 

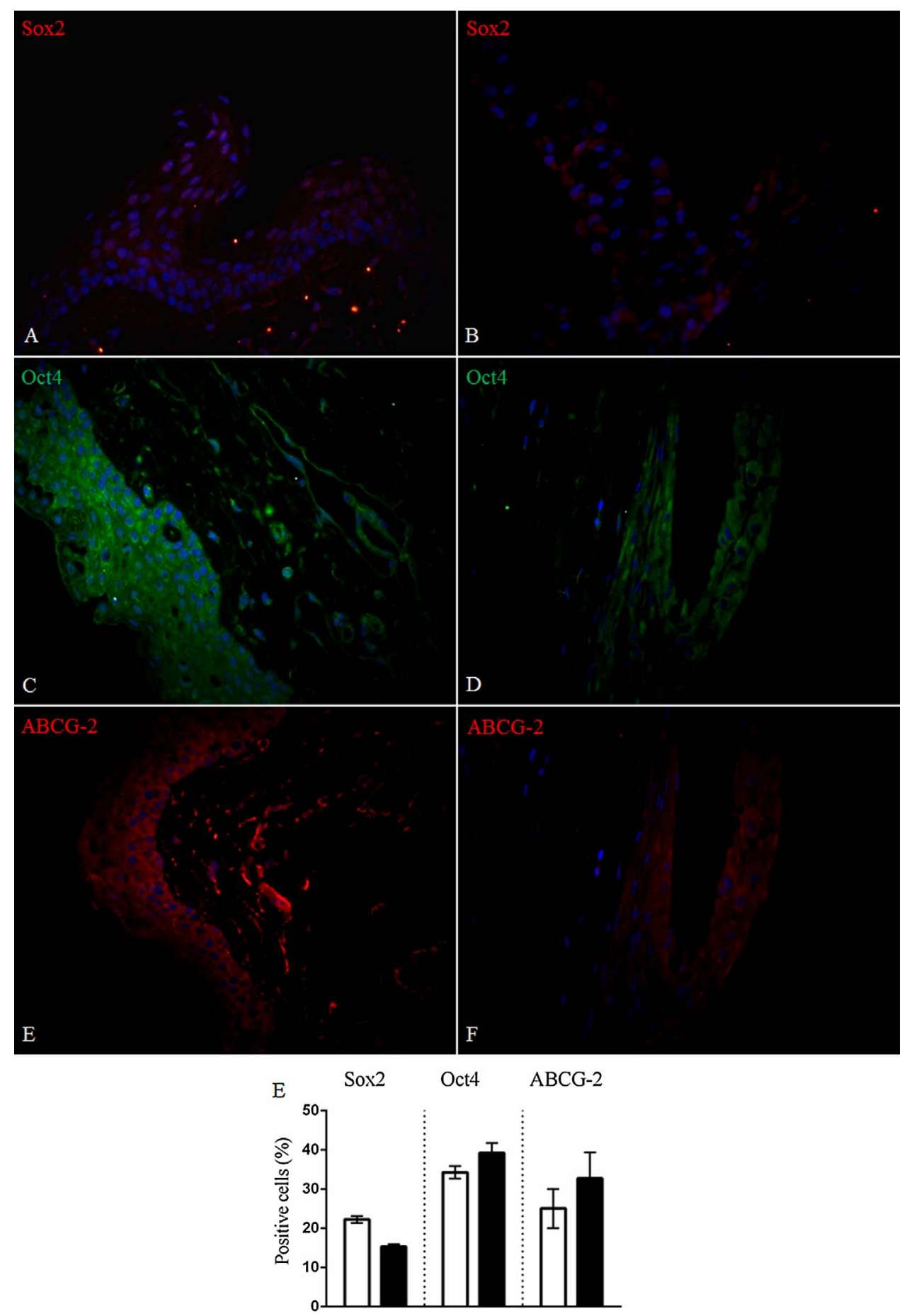

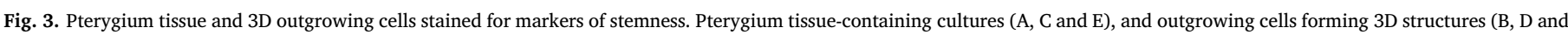

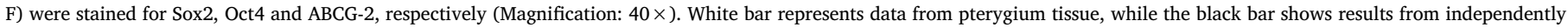
grown $3 \mathrm{D}$ outgrowing cells. Data are expressed as mean $\pm \mathrm{SD}$.

\subsection{Statistical analysis}

Each experiment was performed at least three times and each sample was tested in triplicates. Data are expressed as mean \pm standard deviation (SD). Statistically significant differences were determined by student-t-tests, a $\mathrm{p}$-value $\leq 0.05$ was regarded significant.

\section{Results}

Pterygium morphology depends on two types of cells: fibroblastic which are long-shaped (Fig. 1Aa), and squamous epithelial cells tightly packed together (Fig. 1Ab). After long term cultivation, pterygium formed spontaneous multi-layered structure that was easily tangible and removable from the plate for further analysis (Fig. 1Ac). The viability of the outgrowing cells tested by the Annexin V-FITC/PI assay and Trypan blue method was $(98.6 \pm 1.7 \%$ and $82.6 \pm 6.9 \%)$, respectively (Fig. 1B). The expression of hematopoietic cell surface markers CD34 and CD47 was $(10.8 \pm 12.7 \%$ and $79.1 \pm 17 \%)$, respectively. CD117/c-kit, a progenitor cell marker was low (3.3 $\pm 3.2 \%$ ), while a very high expression of the MSC markers CD90 (87.2 \pm 9.5\%) and CD73 (76.4 $\pm 11 \%)$ were measured, in contrast to the MSC marker CD105 which was $(1.3 \pm 1.4 \%)$. The 


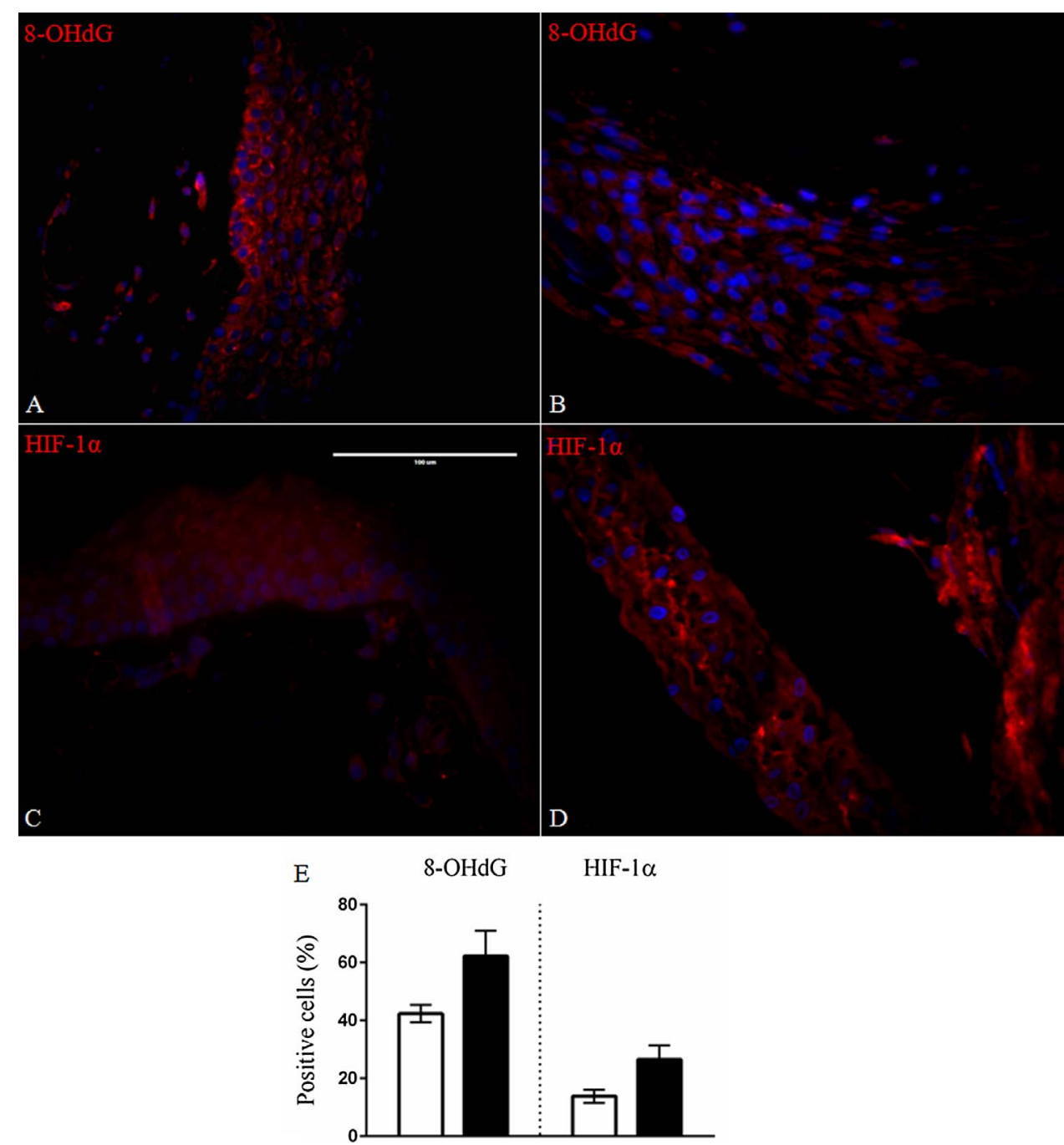

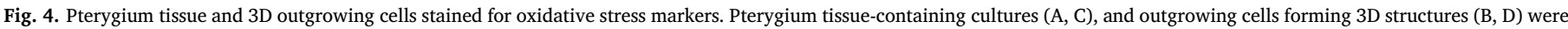

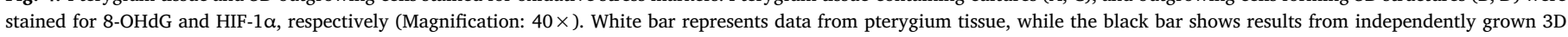
outgrowing cells. Data are expressed as mean \pm SD.

expression of ECM attachment proteins, which is important for the maintenance of the cellular growth were tested next: CD146/MCAM $(2.6 \pm 4.7 \%), \quad$ CD166/ALCAM $(48.1 \pm 18.1 \%)$, CD112/Nectin-2 $(4.1 \pm 4 \%)$ and $\mathrm{CD} 44 /$ homing-associated cell adhesion molecule $(\mathrm{H}-$ CAM) $(41.5 \pm 12.3 \%)$ (Fig. 1C). The expression of surface markers (\%) is summarised in Table 1.

Immunofluorescent staining of a wide range of markers involved in the different pathways were examined in the pterygium grafts obtained directly from surgery and compared to those from long-term cultivated 3D outgrowths from the pterygia. The expression of pluripotency markers (Vim and $\Delta \mathrm{Np} 63)$ was $(26.5 \pm 3.5 \%$ and $13.9 \pm 0.9 \%)$, respectively, in the pterygium graft tissue only, and $(43.7 \pm 4 \%$ and $12.3 \pm 1.5 \%$ ), respectively, in the multi-layered outgrowing cells (Fig. 2), while other stemness markers (Sox2, Oct4 and ABCG-2) showed positivity in $(22.2 \pm 0.9 \%, 34.2 \pm 1.6 \%$ and $25 \pm 5 \%)$ of the cells in the pterygium graft itself, respectively, and $(15.3 \pm 0.6 \%$, $39.2 \pm 2.5 \%$ and $32.7 \pm 6.6$ ), respectively, within the multi-layered outgrowing cells (Fig. 3). Oxidative stress markers (8-OHdG and HIF$1 \alpha$ ) were determined in the pterygium graft tissue $(42.4 \pm 3 \%$ and $13.8 \pm 2.3 \%$ ), respectively and in the multi-layered outgrowing cells $(62.3 \pm 8.6 \%$ and $26.6 \pm 4.8 \%)$, respectively (Fig. 4). The expression of migration and proliferation markers - CXCR4 and Ki-67, was $(27.2 \pm 4.5 \%$ and $5.1 \pm 0.4 \%)$, respectively, in the pterygium graft tissue, and (67.3 $\pm 4.7 \%$ and $1.2 \pm 0.3 \%)$, respectively, in the multi- layered outgrowing cells (Fig. 5). The epithelial cell markers expression (CK19 and CK8-18) was ( $0 \%$ and $24.3 \pm 6.5 \%$ ) for the pterygium graft tissue, and (11.9 $\pm 3.7 \%$ and $0 \%)$, respectively, for the multi-layered outgrowing cells (Fig. 6), while that for the secretory markers (MUC1 and MUC4) was (13.1 $\pm 4.3 \%$ and32.2 $\pm 3.3 \%)$, respectively, for the pterygium graft tissue, and $(63.7 \pm 5.7 \%$ and $55.3 \pm 5 \%)$, respectively, for the multi-layered outgrowing cells (Fig. 7). Expression of all markers (\%) is summarised in Table 2.

The multi-layered outgrowing cells from the pterygium biopsies secreted moderate and low levels of the pro-inflammatory cytokine IL6and IL-8, respectively, which levels were significantly decreased upon treatment with the anti-proliferative agent MMC, in contrast to the level secreted by LESCs (control) for IL-6 ( $p<0.05)$. The IL- 8 secretion upon MMC treatment showed no significant change, although it was lower than that secreted by LESCs (Fig. 8A and B). Both, the inflammatory cytokines' release and the treatment by MMC have clinical relevance in case of recurrent pterygia.

\section{Discussion}

Being a benign process of uncontrolled cell proliferation, pterygium is a common ocular surface disorder which can vary from locally invasive, mild dysplasia to carcinoma in situ, characterized by proliferation, inflammation, fibrosis, angiogenesis and ECM breakdown 


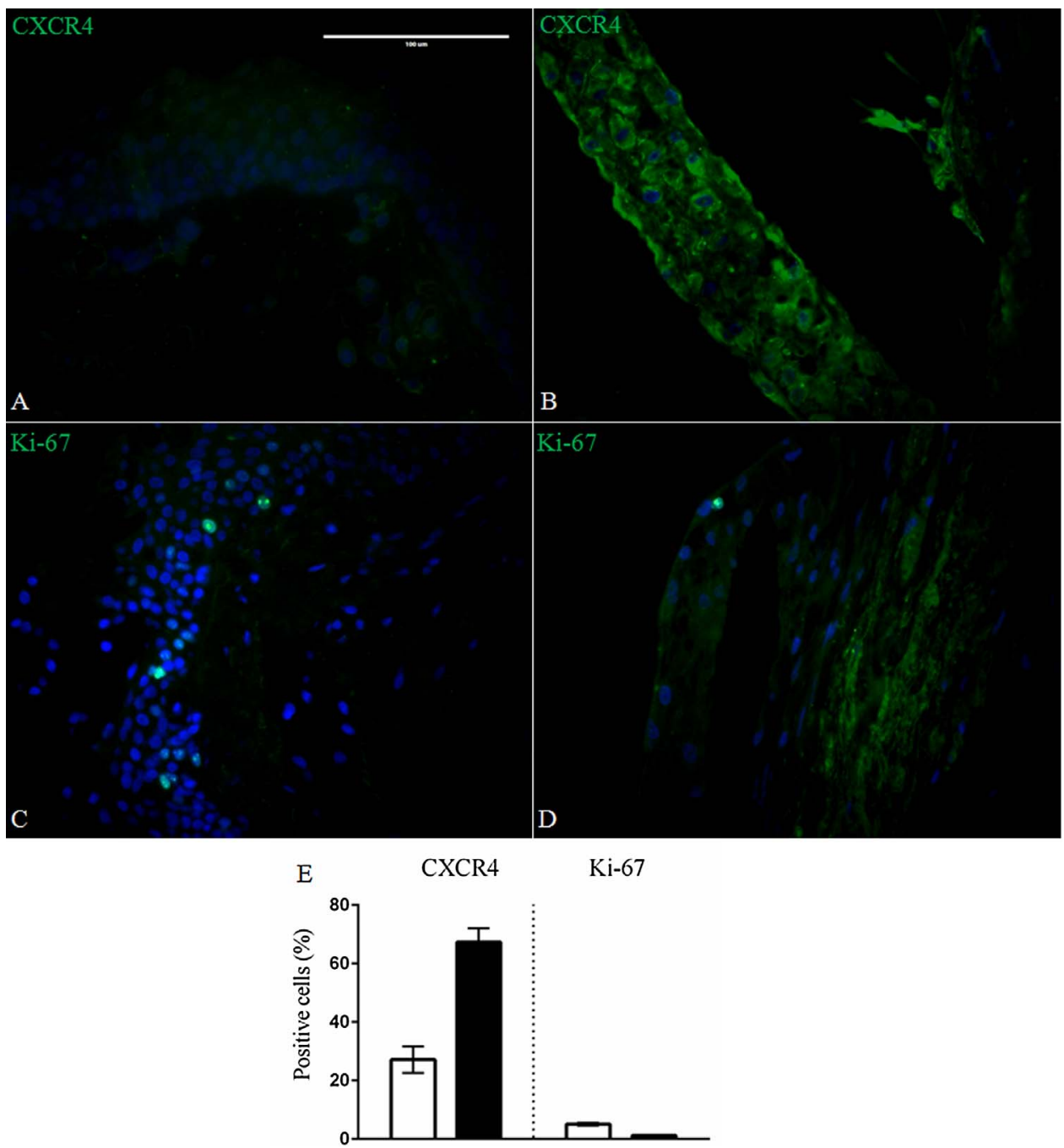

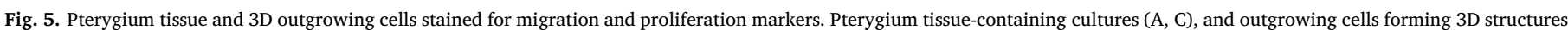

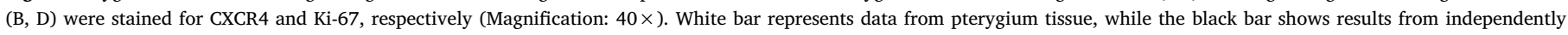
grown 3D outgrowing cells. Data are expressed as mean \pm SD.

[8-10]. The pathogenesis of pterygia is partly unknown, but might be due to an alteration of the normal stationary limbal epithelial basal cells giving rise to a zone of motile daughter cells - pterygium cells, which leave the limbal region and migrate as a group centripetally along the corneal basement membrane dissolving the Bowman's layer. Matrix metalloproteinases (MMP) take a role in the process of squamous metaplasia and goblet cells' hyperplasia [11-14].

Pterygium as a structure consists of a mixture of epithelial and fibroblastic cells, proliferation of which closely determines its recurrence and severity [6]. The stratified outgrowing cell model for pterygium expansion ex vivo shown here has the advantage of giving immediate adherence of the graft to the cell culture plate (e.g. using viscoelastic material), therefore, providing both cell types an equal chance to expand, without the use of any growth factors. The outgrowing cells expressed CK8-18 - a typical epithelial cell marker also expressed by other human corneal cells such as epithelial and endothelial cells $[15,16]$, as well as the LESC marker CK19 $[17,18]$.

Cellular homeostasis or the balance between proliferation and apoptosis can be disrupted in pterygia [19]. The disorder shares many similarities with cancer, in terms of cell proliferation, invasion and recurrence after resection. The proliferation marker Ki-67 has been found to be overexpressed in the epithelial cell layer of pterygium rather than in the stromal fibroblasts, in particular, the head and the body parts compared to the healthy conjunctiva. Accordingly, corneal invasion by the pterygium might be associated with proliferation of the epithelium, although it is clear that fibroblasts play important role in epithelial-mesenchymal interactions [6,20-22]. Ki-67 has also been expressed in conjunctival and eyelid tumours [23], the positivity of which was low in the pterygium graft containing cultures, which was additionally five times less expressed in the multi-layered outgrowing tissue. The SDF-1/CXCR4 signalling pathway has been described in developmental processes and adult angiogenesis to have a role in vascular endothelial cell migration and proliferation [24]. LESCs themselves possess migratory capacity or positivity for CXCR4 [17], while this marker is expressed by vascular endothelial cells in proliferative diabetic retinopathy membranes as well [25]. The pterygium graft-containing cultures showed 2.5 times less positivity for CXCR4 compared to multi-layered outgrowing cell cultures. Vimentin, a crucial cytoskeletal mediator for the repair of cellular function during woundhealing from lens epithelial cells [26] and in LESCs cultivated in longterm cultures [18], was found highly expressed by the pterygium-graft containing and the stratified outgrowing cells. Similarly, $\Delta$ Np63 was expressed at a steady and similar extent in both cell cultures, the protein being known for its role in activation or inhibition of apoptosis in a cell- and tissue-type specific manner. In fact, $\Delta \mathrm{Np} 63 \alpha$ is the most present isoform in the central corneal epithelium which seems to be lost during apoptotic cell death [27]. Furthermore, $\Delta$ Np63 is important in the regulation of LESC proliferation, and its expression in the limbal 


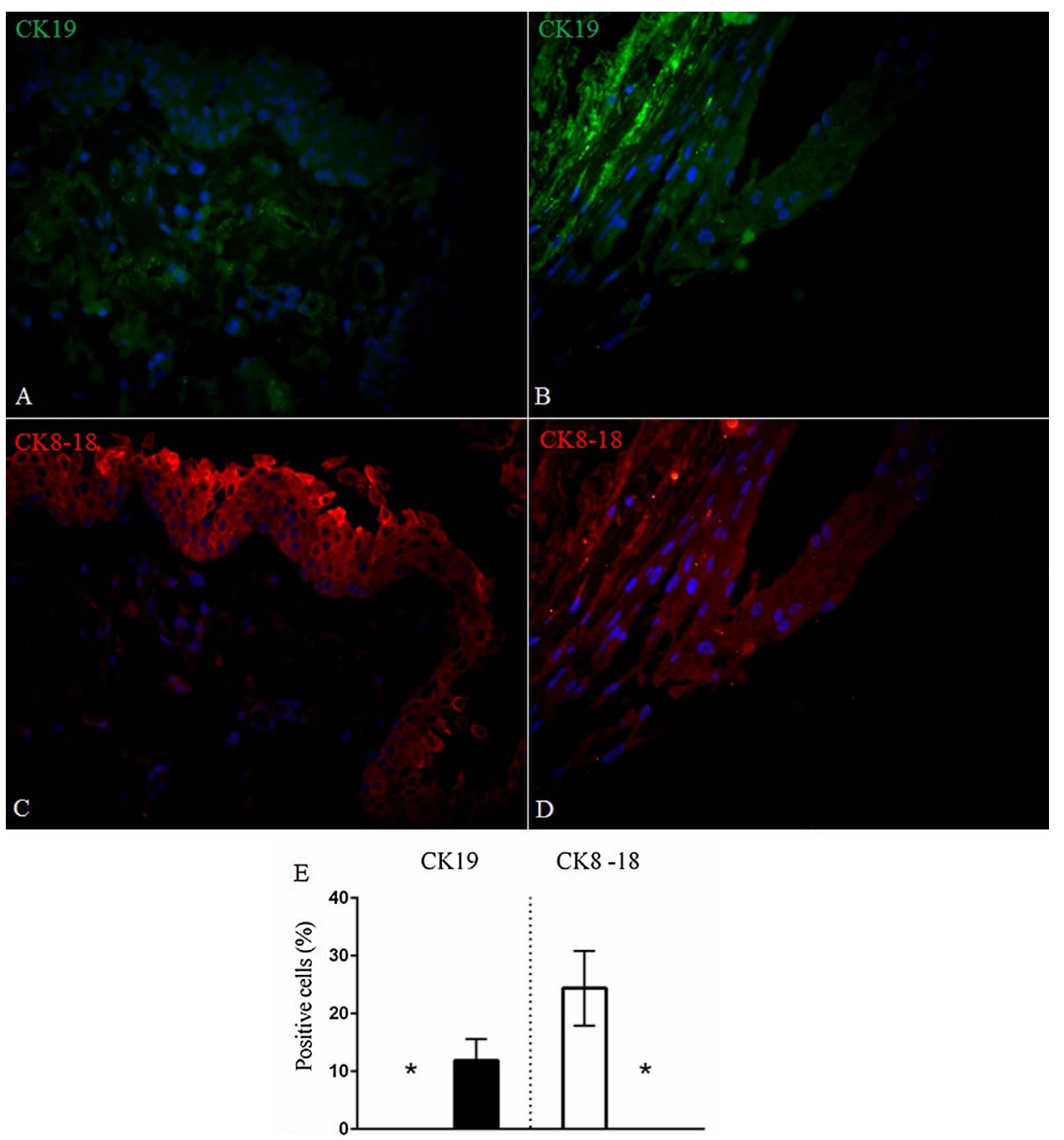

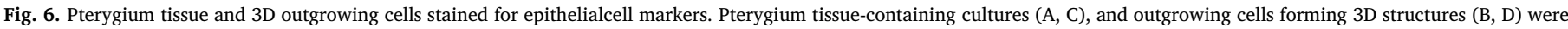

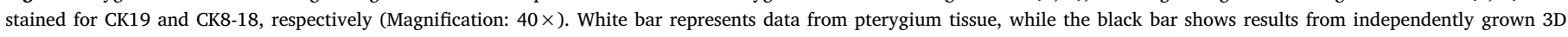
outgrowing cells. Data are expressed as mean \pm SD.

epithelium plays a role in the homeostasis of corneo-limbal epithelium in rabbit limbal epithelial cells [28].

UV-B radiation is considered to be the main factor responsible for pterygium formation due to its capacity to cause oxidative stress, which plays an important role in its recurrence as well. Oxidative stress can induce growth factor production, angiogenesis, chronic inflammation and collagenolysis. When sunlight triggers pterygium inception, the proliferating fibroblasts generate reactive oxygen species that further sustain inflammation [5]. UV light can activate epithelial cells close to the limbus to produce cytokines such as IL-6 and IL-8, and enhance inflammation, proliferation, angiogenesis and anti-apoptosis. IL-8 is secreted from activated monocytes, fibroblasts, endothelial and epithelial cells, while IL- 6 is synthesized by fibroblasts, endothelial cells and keratinocytes in response to cytokines as well as TNF- $\alpha$ and IL-1. In pterygia, IL- 6 and IL- 8 are believed to promote angiogenesis within the epithelium, or to stimulate mitosis in these cells and in fibroblasts together with VEGF, fibroblast growth factor-2 (FGF-2), epidermal growth factor (EGF), and platelet-derived growth factor (PDGF). An abundant immunopositivity for IL- 6 and IL- 8 has indeed been found in pterygium epithelial cells $[4,29]$, while in the 3D pterygium outgrowing cells, only IL-6 appeared to be highly expressed. Likely, the expression of these cytokines is closely related to the factors associated with the niche where pterygia sit in vivo, where they are closely related to the neighbouring limbus and its abundant vasculature underlying it. A balanced antioxidant defence in patients following primary pterygium surgery is also important [30]. 8-OHdG is a ubiquitous marker of oxidative stress with a high mutagenic potential. It is a sensitive and stable biomarker for DNA damage estimation and has been expressed more in the epithelium of the head of primary pterygium compared to the healthy conjunctiva. While pterygium is considered to be a nonmetastatic lesion with limited local invasion, the presence of 8-OHdG could confirm a visible genetic instability which is in contrast to its benign clinical course $[6,31]$.

HIF-1 $\alpha$ plays an important role in the modulation of cell metabolism and survival pathways. A coordinated activation and increase of HIF-1 $\alpha$ and heat shock proteins in pterygium, may represent an adaptive process for the survival of cells undergoing stressful conditions [32].

Pterygium epithelial cells seem to keep their potential to divide and thus support the view of this disease being caused by altered limbal stem cells, also being confirmed by the presence of telomerase in pterygium epithelium [11]. Although there have been reports on the presence of stem cell markers within the eye, to the best of the authors' knowledge, there has been no evidence for their presence in pterygium. Sox 2 has been described as being expressed in many epithelial cell types, including conjunctival epithelial cells. In the conjunctival ocular surface epithelial cells, but not ocular stromal cells, the pluripotent stem cell marker Oct4 has been found expressed [33]. ABCG-2 has a role in the maintenance of retinal stem cells under the regulation of 

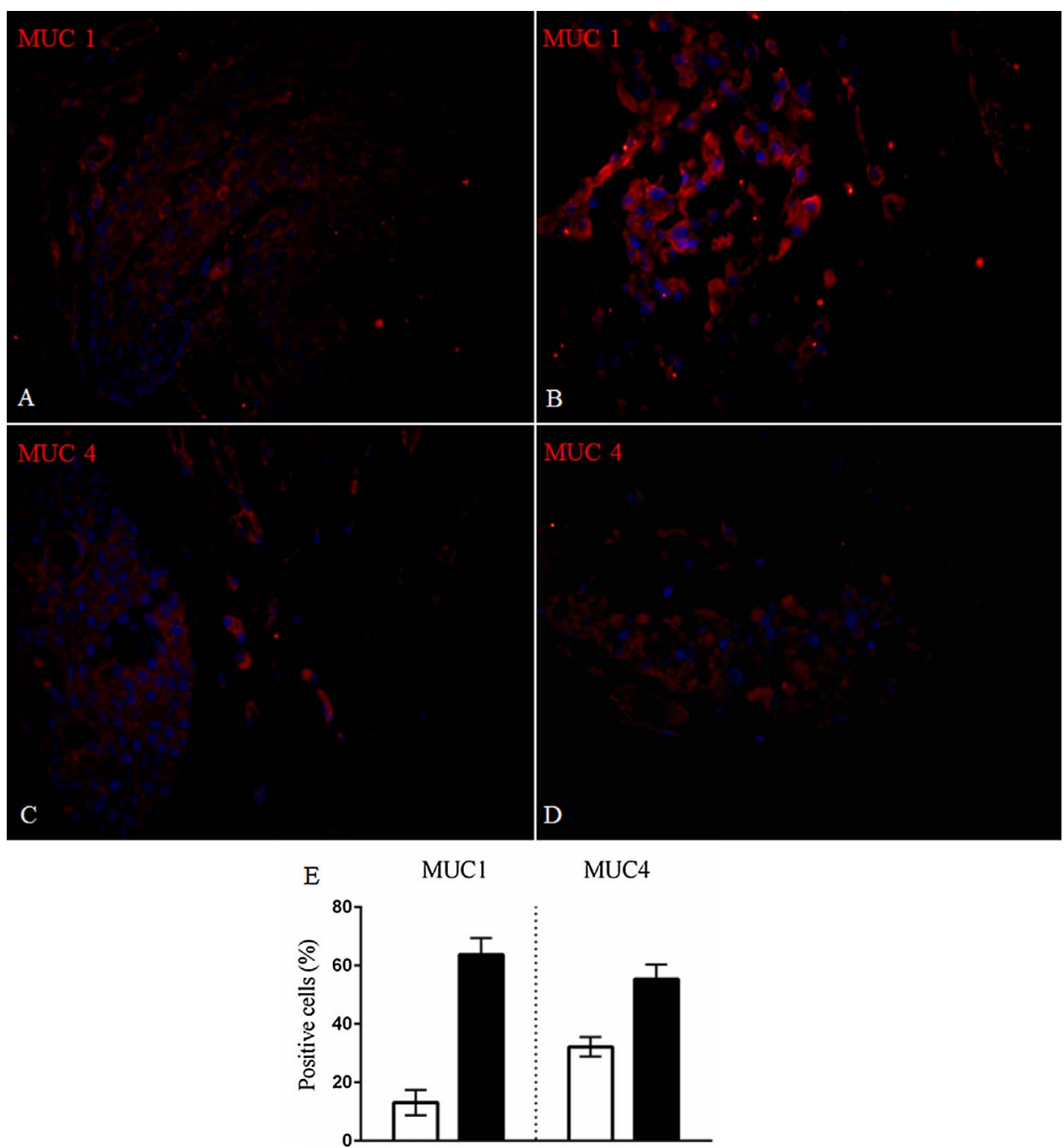

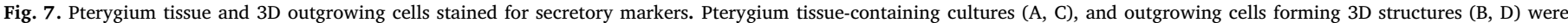

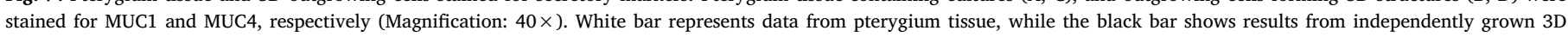
outgrowing cells. Data are expressed as mean \pm SD.

Table 2

Expression of a wide range of markers expressed in pterygium grafts obtained directly from surgery and compared to long-term cultivated 3D outgrowths from pterygium shown as percent (\%).

\begin{tabular}{|c|c|c|c|}
\hline & & Pterygium graft & $\begin{array}{l}\text { Multi-layered } \\
\text { outgrowing pterygium } \\
\text { cells }\end{array}$ \\
\hline Pluripotency markers & $\begin{array}{l}\text { Vim } \\
\Delta \mathrm{Np} 63\end{array}$ & $\begin{array}{l}26.5 \pm 3.5 \% \\
13.9 \pm 0.9 \%\end{array}$ & $\begin{array}{l}43.7 \pm 4 \% \\
12.3 \pm 1.5 \%\end{array}$ \\
\hline Stemness markers & $\begin{array}{l}\text { Sox2 } \\
\text { Oct4 } \\
\text { ABCG-2 }\end{array}$ & $\begin{array}{l}22.2 \pm 0.9 \% \\
34.2 \pm 1.6 \% \\
25 \pm 5 \%\end{array}$ & $\begin{array}{l}15.3 \pm 0.6 \% \\
39.2 \pm 2.5 \% \\
32.7 \pm 6.6 \%\end{array}$ \\
\hline $\begin{array}{l}\text { Oxidative stress and } \\
\text { hypoxia markers }\end{array}$ & $\begin{array}{l}\text { OHdG } \\
\text { HIF-1 } \alpha\end{array}$ & $\begin{array}{l}42.4 \pm 3 \% \\
13.8 \pm 2.3 \%\end{array}$ & $\begin{array}{l}62.3 \pm 8.6 \% \\
26.6 \pm 4.8 \%\end{array}$ \\
\hline $\begin{array}{l}\text { Migration and } \\
\text { proliferation } \\
\text { markers }\end{array}$ & $\begin{array}{l}\text { CXCR4 } \\
\text { Ki-67 }\end{array}$ & $\begin{array}{l}27.2 \pm 4.5 \% \\
5.1 \pm 0.4 \%\end{array}$ & $\begin{array}{l}67.3 \pm 4.7 \% \\
1.2 \pm 0.3 \%\end{array}$ \\
\hline Epithelial cell markers & $\begin{array}{l}\text { CK19 } \\
\text { CK8-18 }\end{array}$ & $\begin{array}{l}0 \% \\
24.3 \pm 6.5 \%\end{array}$ & $\begin{array}{l}11.9 \pm 3.7 \% \\
0 \%\end{array}$ \\
\hline Secretory markers & $\begin{array}{l}\text { MUC1 } \\
\text { MUC4 }\end{array}$ & $\begin{array}{l}13.1 \pm 4.3 \% \\
32.2 \pm 3.3 \%\end{array}$ & $\begin{array}{l}63.7 \pm 5.7 \% \\
55.3 \pm 5 \%\end{array}$ \\
\hline
\end{tabular}

Notch signalling. The expression of ABCG-2 in canine limbal epithelial cells has been considered a useful marker for presence of putative corneal epithelial stem cells and proliferation $[34,35]$. The ex vivo 3D tissue engineered pterygium outgrowths and the graft-containing cultures expressed all of these stem cell markers (Sox2, Oct4 and ABCG-2).

It is believed that the multifunctional molecules MUC1 and MUC4 are involved in the barrier function, protection and lubrication of the ocular surface, signalling and that they are osmosensors. These proteins can be expressed by both corneal and conjunctival epithelia [36,37], while their expression in the pterygium graft-containing cultures and the stratified outgrowing cells was clearly high, probably making the ex vivo model for pterygium being close to a goblet cell hyperplasia as well.

MMC has often been used to reduce recurrence of pterygium in connection with conjunctival autografts, amniotic membrane transplantation and radiation or chemotherapeutical agents' treatment $[38,39]$. MMC suppresses the proliferation of fibroblasts by inhibiting DNA synthesis, hence it can also affect normal tissues and cause complications such as scleral necrosis, corneal perforation, corneal oedema, secondary glaucoma, corneal calcification and cataracts, thus it must be used with caution [1]. In this study, MMC reduced the level of secreted cytokines (in particular IL-6), which provides a combined anti-inflammatory and anti-proliferative therapy for pterygium at a 
A

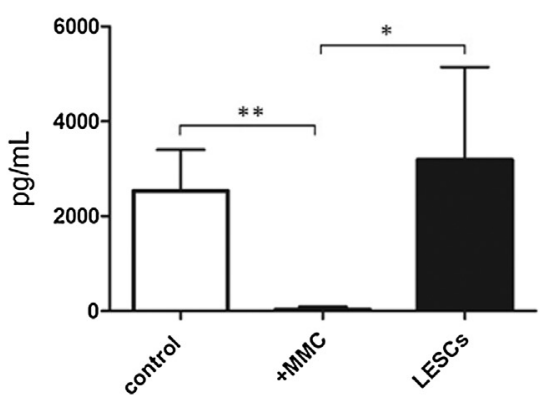

B

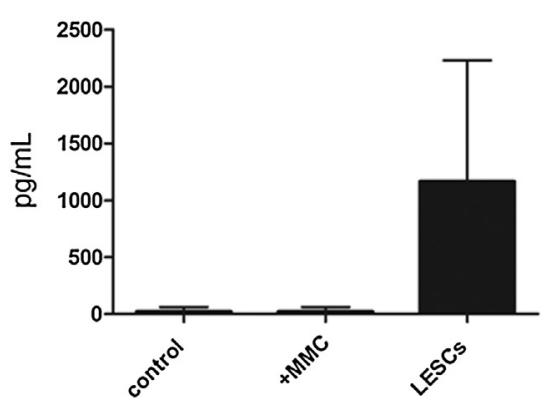

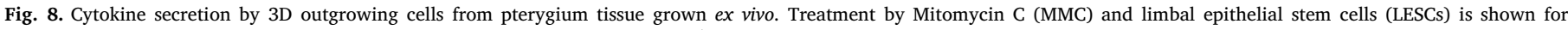
comparison. The significant data for secretion of IL-6 is presented with asterisk ( ${ }^{*}$ ), while IL-8 showed no significant expression.

cellular and molecular level.

The pterygium outgrowing cells were still viable after having undergone more than three months cultivation time, which was further confirmed by the high level expression of CD47. The surface marker profile of ex vivo cultivated outgrowing cells showed that CD44, a protein expressed actively on dividing cells [40], is moderately expressed in the stratified outgrowing cells. The expression of ECM attachment proteins, which is vital for the maintenance of cellular growth within the pterygium, was low (CD146/MCAM, CD112/Nectin2) and moderate (CD166/ALCAM, CD44/H-CAM). Those markers could also be found in LESCs, while the expression of CD73 and CD105 in 3D outgrowing cells from pterygium was in general lower than that found in LESCs [17]. Expression of CD105 has been described previously to have a role in neovascular endothelial cells formation in the subepithelial area of primary pterygia, while a correlation between the expression of VEGF in the stroma and CD105-MVD in primary pterygia has also been proposed. Overexpression of VEGF and CD105-MVD can contribute to pterygium progression by increasing angiogenesis and growth [41]. Expression of the hematopoietic cell surface markers CD34 and 'don't eat me' signal CD47 in the 3D outgrowing cell from pterygium cells was low and high, respectively. The population of 3D outgrowing cells from pterygium contained a low level of the early progenitor cell marker CD117/c-kit.

In conclusion, it has been demonstrated that human pterygium explants can give rise to 3D outgrowing cells in a medium containing FBS as the only growth supplement. The cells were viable, could proliferate and migrate out of the grafts and form a stratified structure very much like the one in vivo. The expanding cells carried proteins related to an undifferentiated state, but also a commitment towards epithelial lineage. Stemness markers suggest a flexible cell phenotype in the long-term cultures. Manipulating the cell sheets was similar to handling primary human tissues, presuming a possibility for use in tissue engineering and drug discovery.

\section{Acknowledgements}

NJ has been supported by a Campus Hungary grant, while DJS has been supported by an EU COST Action BM1302 travel grant to perform parts of their experiments at the host site at the Norwegian Center for Stem Cell Research/Center for Eye Research, University of Oslo, Norway. GP and the Stem Cells and Eye Research Laboratory, Department of Ophthalmology, Faculty of Medicine, University of Szeged, Hungary, have been supported by the National Brain Research Program (KTIA_NAP_13-A_III/9). Furthermore, the project was also funded through the Center for Eye Research (CER), Department of Ophthalmology, Oslo University Hospital and University of Oslo and the Norwegian Financial Mechanism 2009-2014 under Project Contract no. MSMT-28477/2014, project 7F14156. We like to thank Charlotte L. Ness, Kristiane Haug Berg and staff at the Center for Eye Research, Department of Ophthalmology,
Oslo University Hospital for their technical support and input. The authors would like to thank Dr. Agate Noer for her technical and proofreading help of this work.

\section{Appendix A. Supplementary data}

Supplementary data associated with this article can be found, in the online version, at http://dx.doi.org/10.1016/j.clae.2017.04.002

\section{References}

[1] S. Hwang, S. Choi, A comparative study of topical mitomycin C, cyclosporine, and bevacizumab after primary pterygium surgery, Korean J. Ophthalmol. 29 (6) (2015) 375-381.

[2] E. Clearfield, V. Muthappan, X. Wang, I.C. Kuo, Conjunctival autograft for pterygium, Cochrane Database Syst. Rev. 2 (2016) CD011349.

[3] E.T. Detorakis, G. Kymionis, M. Tsatsos, D.A. Spandidos, Pterygium concomitant with other ocular surface lesions: clinical implications and pathogenetic links, Exp. Ther. Med. 11 (1) (2016) 69-72.

[4] K.W. Kim, S.H. Park, J.C. Kim, Fibroblast biology in pterygia, Exp. Eye Res. 142 (2016) 32-39.

[5] P. Anguria, J. Kitinya, S. Ntuli, T. Carmichael, The role of heredity in pterygium development, Int. J. Ophthalmol. 7 (3) (2014) 563-573.

[6] E. Cardenas-Cantu, J. Zavala, J. Valenzuela, J.E. Valdez-Garcia, Molecular basis of pterygium development, Semin. Ophthalmol. (2014) 1-17.

[7] S. Andjelic, X. Lumi, Z. Vereb, N. Josifovska, A. Facsko, M. Hawlina, G. Petrovski, A simple method for establishing adherent ex vivo explant cultures from human eye pathologies for use in subsequent calcium imaging and inflammatory studies, J. Immunol. Res. 2014 (2014) 232659, http://dx.doi.org/10.1155/2014/232659 Epub 2014 Sep 4 https://www.ncbi.nlm.nih.gov/pubmed/25276840.

[8] J. Chui, M.T. Coroneo, L.T. Tat, R. Crouch, D. Wakefield, N. Di Girolamo, Ophthalmic pterygium: a stem cell disorder with premalignant features, Am. J. Pathol. 178 (2) (2011) 817-827.

[9] P. Demurtas, G. Orru, L. Coni, M. Corrias, P. Sirigu, I. Zucca, E. Demurtas, C. Maxia, D. Piras, S. Lai, M.T. Perra, Association between the ACE insertion/deletion polymorphism and pterygium in Sardinian patients: a population based case-control study, BMJ Open 4 (10) (2014) e005627.

[10] T. Liu, Y. Liu, L. Xie, X. He, J. Bai, Progress in the pathogenesis of pterygium, Curr. Eye Res. 38 (12) (2013) 1191-1197.

[11] N. Di Girolamo, J. Chui, M.T. Coroneo, D. Wakefield, Pathogenesis of pterygia: role of cytokines, growth factors, and matrix metalloproteinases, Prog. Retin. Eye Res. 23 (2) (2004) 195-228.

[12] N. Dushku, T.W. Reid, Immunohistochemical evidence that human pterygia originate from an invasion of vimentin-expressing altered limbal epithelial basal cells, Curr. Eye Res. 13 (7) (1994) 473-481.

[13] F.H. Zaidi, P.A. Bloom, M.C. Corbett, Limbal stem cell deficiency: a clinical chameleon, Eye (Lond.) 17 (7) (2003) 837-839.

[14] N. Dushku, M.K. John, G.S. Schultz, T.W. Reid, Pterygia pathogenesis: corneal invasion by matrix metalloproteinase expressing altered limbal epithelial basal cells, Arch. Ophthalmol. 119 (5) (2001) 695-706.

[15] S. Merjava, A. Neuwirth, V. Mandys, K. Jirsova, Cytokeratins 8 and 18 in adult human corneal endothelium, Exp. Eye Res. 89 (3) (2009) 426-431.

[16] M. Kasper, P. Stosiek, B. Lane, Cytokeratin and vimentin heterogeneity in human cornea, Acta Histochem. 93 (2) (1992) 371-381.

[17] R. Albert, Z. Vereb, K. Csomos, M.C. Moe, E.O. Johnsen, O.K. Olstad, B. Nicolaissen, E. Rajnavolgyi, L. Fesus, A. Berta, G. Petrovski, Cultivation and characterization of cornea limbal epithelial stem cells on lens capsule in animal material-free medium, PLoS One 7 (10) (2012) e47187.

[18] D.J. Szabo, A. Noer, R. Nagymihaly, N. Josifovska, S. Andjelic, Z. Vereb, A. Facsko, M.C. Moe, G. Petrovski, Long-term cultures of human cornea limbal explants form 3D structures ex vivo - implications for tissue engineering and clinical applications, PLoS One 10 (11) (2015) e0143053.

[19] P. Sakoonwatanyoo, D.T. Tan, D.R. Smith, Expression of p63 in pterygium and 
normal conjunctiva, Cornea 23 (1) (2004) 67-70.

[20] S. Kase, S. Takahashi, I. Sato, K. Nakanishi, K. Yoshida, S. Ohno, Expression of p27(KIP1) and cyclin D1, and cell proliferation in human pterygium, Br. J. Ophthalmol. 91 (7) (2007) 958-961.

[21] K. Liang, Z. Jiang, B.Q. Ding, P. Cheng, D.K. Huang, L.M. Tao, Expression of cell proliferation and apoptosis biomarkers in pterygia and normal conjunctiva, Mol. Vis. 17 (2011) 1687-1693.

[22] M. Nubile, C. Curcio, M. Lanzini, R. Calienno, M. Iezzi, A. Mastropasqua, M. Di Nicola, L. Mastropasqua, Expression of CREB in primary pterygium and correlation with cyclin D1, ki-67, MMP7, p53, p63, Survivin and Vimentin, Ophthalmic Res. 50 (2) (2013) 99-107.

[23] J. Reszec, L. Kanczuga-Koda, M. Sulkowska, M. Koda, J. Cylwik, M. BarwijukMachala, S. Sulkowski, An evaluation of Ki-67 and PCNA expression in conjunctival and eyelid tumours, Folia Morphol. (Warsz) 63 (1) (2004) 95-98.

[24] G.A. Strasser, J.S. Kaminker, M. Tessier-Lavigne, Microarray analysis of retinal endothelial tip cells identifies CXCR4 as a mediator of tip cell morphology and branching, Blood 115 (24) (2010) 5102-5110.

[25] A.M. Abu El-Asrar, S. Struyf, G. Opdenakker, J. Van Damme, K. Geboes, Expression of stem cell factor/c-kit signaling pathway components in diabetic fibrovascular epiretinal membranes, Mol. Vis. 16 (2010) 1098-1107.

[26] A.S. Menko, B.M. Bleaken, A.A. Libowitz, L. Zhang, M.A. Stepp, J.L. Walker, A central role for vimentin in regulating repair function during healing of the lens epithelium, Mol. Biol. Cell 25 (6) (2014) 776-790.

[27] D.M. Robertson, S.I. Ho, H.D. Cavanagh, C-terminal cleavage of DeltaNp63alpha is associated with TSA-induced apoptosis in immortalized corneal epithelial cells, Invest. Ophthalmol. Vis. Sci. 51 (8) (2010) 3977-3985.

[28] Y.J. Hsueh, P.C. Kuo, J.K. Chen, Transcriptional regulators of the DeltaNp63: their role in limbal epithelial cell proliferation, J. Cell. Physiol. 228 (3) (2013) 536-546.

[29] N. Di Girolamo, R.K. Kumar, M.T. Coroneo, D. Wakefield, UVB-mediated induction of interleukin-6 and -8 in pterygia and cultured human pterygium epithelial cells, Invest. Ophthalmol. Vis. Sci. 43 (11) (2002) 3430-3437.

[30] A. Kormanovski, F. Parra, A. Jarillo-Luna, E. Lara-Padilla, J. Pacheco-Yepez, R. Campos-Rodriguez, Oxidant/antioxidant state in tissue of prymary and recurrent pterygium, BMC Ophthalmol. 14 (2014) 149.
[31] M.T. Perra, C. Maxia, A. Corbu, L. Minerba, P. Demurtas, R. Colombari, D. Murtas, S. Bravo, F. Piras, P. Sirigu, Oxidative stress in pterygium: relationship between p53 and 8-hydroxydeoxyguanosine, Mol. Vis. 12 (2006) 1136-1142.

[32] D. Pagoulatos, N. Pharmakakis, J. Lakoumentas, M. Assimakopoulou, Etaypoxiainducible factor-1alpha, von Hippel-Lindau protein, and heat shock protein expression in ophthalmic pterygium and normal conjunctiva, Mol. Vis. 20 (2014) 441-457.

[33] M.W. Poon, J. He, X. Fang, Z. Zhang, W. Wang, J. Wang, F. Qiu, H.F. Tse, W. Li, Z. Liu, Q. Lian, Human ocular epithelial cells endogenously expressing SOX2 and OCT4 yield high efficiency of pluripotency reprogramming, PLoS One 10 (7) (2015) e0131288.

[34] M. Morita, N. Fujita, A. Takahashi, E.R. Nam, S. Yui, C.S. Chung, N. Kawahara, H.Y. Lin, K. Tsuzuki, T. Nakagawa, R. Nishimura, Evaluation of ABCG2 and p63 expression in canine cornea and cultivated corneal epithelial cells, Vet. Ophthalmol. 18 (1) (2015) 59-68.

[35] S. Bhattacharya, A. Das, K. Mallya, I. Ahmad, Maintenance of retinal stem cells by Abcg2 is regulated by notch signaling, J. Cell Sci. 120 (Pt. 15) (2007) 2652-2662.

[36] M. Berry, R.B. Ellingham, A.P. Corfield, Membrane-associated mucins in normal human conjunctiva, Invest. Ophthalmol. Vis. Sci. 41 (2) (2000) 398-403.

[37] B. Govindarajan, I.K. Gipson, Membrane-tethered mucins have multiple functions on the ocular surface, Exp. Eye Res. 90 (6) (2010) 655-663.

[38] C.J. Jaworski, M. Aryankalayil-John, M.M. Campos, R.N. Fariss, J. Rowsey, N. Agarwalla, T.W. Reid, N. Dushku, C.A. Cox, D. Carper, G. Wistow, Expression analysis of human pterygium shows a predominance of conjunctival and limbal markers and genes associated with cell migration, Mol. Vis. 15 (2009) 2421-2434.

[39] E. Toker, M. Eraslan, Recurrence after primary pterygium excision: amniotic membrane transplantation with fibrin glue versus conjunctival autograft with fibrin glue, Curr. Eye Res. 41 (1) (2016) 1-8.

[40] N.P. Liu, W.L. Roberts, L.P. Hale, M.C. Levesque, D.D. Patel, C.L. Lu, G.J. Jaffe, Expression of CD44 and variant isoforms in cultured human retinal pigment epithelial cells, Invest. Ophthalmol. Vis. Sci. 38 (10) (1997) 2027-2037.

[41] J. Zhang, M. Zhang, X. Li, T. Zheng, G. Mu, W. Liu, H. Xie, X. Liu, Correlation of vascular endothelial growth factor and CD105-microvascular density in primary pterygium, J. Huazhong Univ. Sci. Technol. Med. Sci. 31 (4) (2011) 560-564. 